\title{
Duchenne muscular dystrophy:A clinical, histopathological and genetic study at a neurology tertiary care center in southern India
}

\author{
Bhairavi Swaminathan, G. N. Shubha, D. Shubha, A. Ram Murthy, H. B. Kiran Kumar, S. Shylashree ${ }^{1}$, N. Gayathri ${ }^{2}$ \\ R. Jamuna ${ }^{3}$, Sanjeev Jain, Meera Purushottam, A. Nalini ${ }^{1}$ \\ Departments of Molecular Genetics Laboratory, ${ }^{1}$ Neurology, ${ }^{2}$ Neuropathology, and ${ }^{3}$ Neuropsychology, National Institute of Mental \\ Health and Neurosciences, Bangalore, India
}

\section{Address for correspondence: Dr. A. Nalini, \\ National Institute of Mental Health and Neurosciences, Neuroscience Faculty Block, Bangalore - 560 029, India. E-mail: atchayaramnalini@yahoo. co.in}

DOI: $10.4103 / 0028-3886.59468$

\begin{abstract}
Background: Duchenne muscular dystrophy (DMD) is the most common muscular dystrophy that affects young boys and the dystrophin gene on the $\mathrm{X}$ chromosome has been found to be associated with the disorder. Materials and Methods: In this prospective study, 112 clinically diagnosed DMD patients had muscle biopsy and were tested for exon deletions. Genotyping was also carried out at STR44, STR45, STR49 and STR 50 markers in 15 families. Results: Of the 112 clinically suspected DMD patients, the diagnosis of DMD was confirmed by histopathology and/or genetics in 101 patients. The mean age of onset was $3.1 \pm 1.44$ years ( $1-6$ years) and the mean age at presentation was $8.0 \pm 3.1$ years (1 1 - 18.0 years). Delayed motor milestones were present in 63(62.3\%) patients. The mean creatine kinase value was $11822.64 \pm 8206.90$ U/L (1 240-57,700). Eighty-four patients had muscle biopsy and immunohistochemistry was done in 60 muscle samples, all of which demonstrated absence of dystrophin staining. Of the 60 dystrophin-negative cases, $73 \%$ showed deletion of at least one exon. Single exon deletion was found in 20.4\%. Distal hotspot Exons 45, 47, 49 and 50 were the commonly deleted xenons and the deletion rates were $36 \%, 35 \%, 33.7 \%$ and $38.5 \%$ respectively. Conclusions: In this study population in south India the deletion rate was $73 \%$ and were more frequent in the distal end exon. With the availability of genetic analysis, the first investigation of choice in DMD should be genetic studies and muscle biopsy should be considered only if the genetic tests are negative or not available.
\end{abstract}

Key words: Duchenne muscular dystrophy, dystrophin gene, exon deletions

\section{Introduction}

Duchenne muscular dystrophy (DMD) is the most common form of all muscular dystrophies with an incidence rate of 1:3500 live male births. ${ }^{[1]}$ Earlier, histopathology was the most widely accepted method of distinguishing the types of muscular dystrophies. ${ }^{[1]}$ Availability of genetic tests make it possible to diagnose these disorders early and also avoid invasive procedures like muscle biopsy. The gene responsible for DMD is one of the longest genes, spanning a length of $2.3 \mathrm{MB}$ and contains 79 exons. ${ }^{[2]}$ The disease is caused by mutations in the dystrophin gene, which leads to the loss of function of the protein. ${ }^{[3]}$ Deletions account for $60-65 \%$ cases in DMD; duplications for 5-6\% and point mutations for the remaining cases. ${ }^{[4-7]}$ Using primers targeting 18 hotspot exons in the dystrophin gene, $98 \%$ of deletions can be detected. The proximal hotspot encompasses Exons 3-7 and the distal hotspot Exons 45-51..$^{[8]}$ The genetic diagnosis for DMD involves multiplex polymerase 
chain reaction analysis of 27 exons which include these hotspots. Dinucleotide repeat polymorphism-based genetic analysis at short tandem repeats loci within the gene and near the deleted exon can ascertain carrier status in the majority of female relatives. ${ }^{[4,9]}$ The present study reports the analysis of exonic deletions in 112 clinically suspected DMD patients.

\section{Materials and Methods}

The study was approved by the Institutional Ethics Committee. A prospective study was performed on 112 definite or probable DMD patients. Diagnosis was based on clinical characteristics, elevated serum creatine kinase (CK) and electromyographic features. Other evidences for the diagnosis of DMD prior to genetic analysis included: The absence of dystrophin staining in muscle biopsy and X-linked inheritance pattern of a myopathy clinically compatible with DMD. General intelligence was tested using Binet Kamath Test of Intelligence. ${ }^{[10]}$ Based on the intelligence quotient they were classified as mild mental retardation(38-63), borderline intelligence (63-74), dull normal (75-86), average intelligence (87-112), and bright normal (113-124).

\section{Muscle biopsy}

Muscle biopsies were obtained by the open method from quadriceps or biceps muscles. Immunostaining with monoclonal antibodies to dystrophin $(1,2,3)$ (Novocastra, UK)., a-Sarcoglycan and a-2 Laminin (Merosin) as primary and HRP tagged LSAB as secondary was carried out.

\section{Genetic analysis}

After written informed consent, genomic DNA was isolated from blood by the salting out method as described by Miller et al.$^{[11]}$ Multiplex polymerase chain reactions (PCR) were carried out for 27 exons according to Chamberlain et al., and Beggs et al. ${ }^{[8,12]}$ PCR products were resolved on 9\% PAGE gels or 2\% Agarose gels, and the gels were analyzed for exonic deletions by the presence or absence of a corresponding band.

\section{Microsatellite analysis}

Genotyping was carried out at STR 45, STR 49 and STR 50, highly polymorphic dinucleotide (CA)n loci in the dystrophin gene. ${ }^{[9]}$ The FAM-labeled products were electrophoresed on a 5\% ABI377 sequencing gel.

\section{Results}

\section{Clinical findings}

Of the 112 clinically suspected DMD boys, the diagnosis of DMD was confirmed by histopathology and immunohistochemistry and/or genetic studies in
Table 1: Salient clinical features of the patients $(\mathrm{N}=101)$ with Duchenne muscular dystrophy (percentage/range)

\begin{tabular}{|c|c|}
\hline Features & $\mathbf{N}=101$ \\
\hline Mean age of onset (years) & $3.1 \pm 1.44(1-6)$ \\
\hline Mean age at presentation (years) & $8.0 \pm 3.1(1.1-18.0)$ \\
\hline Consanguinity & 19 \\
\hline Delayed motor milestones & 63 \\
\hline Family history [sibling(s)] & 21 \\
\hline Progressive lower limb weakness & 101 \\
\hline Calf hypertrophy & 91 \\
\hline Repeated falls & 87 \\
\hline Toe walking & 45 \\
\hline LL proximal muscle weakness & 101 \\
\hline \multicolumn{2}{|l|}{ Contractures } \\
\hline Ankles & 89 \\
\hline Hamstrings & 24 \\
\hline Iliopsoas & 20 \\
\hline Biceps & 5 \\
\hline \multicolumn{2}{|l|}{ Hypertrophy } \\
\hline Deltoid & 34 \\
\hline Triceps & 16 \\
\hline Quadriceps & 19 \\
\hline Calf & 91 \\
\hline Extensor digitorum brevis & 49 \\
\hline \multicolumn{2}{|l|}{ Wasting } \\
\hline Shoulder girdle & 53 \\
\hline Thigh muscles & 25 \\
\hline Legs & 12 \\
\hline \multicolumn{2}{|l|}{ Neck muscles } \\
\hline Flexors & 101 \\
\hline Extensors & 60 \\
\hline \multicolumn{2}{|l|}{ Weakness -upper limbs } \\
\hline Deltoid & 90 \\
\hline Pectorals & 101 \\
\hline Biceps & 90 \\
\hline Triceps & 95 \\
\hline Distal & 30 \\
\hline \multicolumn{2}{|l|}{ Weakness-lower limbs } \\
\hline Gluteus maximus/iliopsoas & 101 \\
\hline Hip abductors/adductors & 85 \\
\hline Quadriceps & 100 \\
\hline Hamstrings & 70 \\
\hline Tibialis anterior & 67 \\
\hline Gastrocnemius & 30 \\
\hline \multicolumn{2}{|l|}{ Investigations } \\
\hline CK (units/L) & $11822.6 \pm 8206.9(1240-57,700)$ \\
\hline Mothers $(n=57)$ & $270.3 \pm 417.3(52-2679)$ \\
\hline \multicolumn{2}{|l|}{ Electrocardiography $(n=70)$} \\
\hline Abnormal q-waves & $23(32.8)$ \\
\hline Right ventricular dominance & $24(34.3)$ \\
\hline \multicolumn{2}{|l|}{ 2D- Echocardiography $(n=52)$} \\
\hline Normal & $50(96.1)$ \\
\hline Bicuspid aortic valve & $1(2.0)$ \\
\hline Dilated cardiomyopathy & $1(2.0)$ \\
\hline \multicolumn{2}{|l|}{ Electromyography $(n=56)$} \\
\hline Myopathic process & $56(100.0)$ \\
\hline \multicolumn{2}{|l|}{ Intelligence quotient $(\mathrm{n}=81)$} \\
\hline Mild mental retardation (38-63) & $12(14.8)$ \\
\hline Borderline intelligence (63-74) & $27(33.3)$ \\
\hline Dull normal (75-86) & $22(27.1)$ \\
\hline Average intelligence (87-112) & $16(19.7)$ \\
\hline Bright normal (113-124) & $4(4.9)$ \\
\hline
\end{tabular}

101 boys. The clinical details are described in Table 1. All boys presented with progressive proximal muscle weakness particularly of the lower limbs and the majority (90\%) complained of calf muscle hypertrophy. 


\section{Investigations}

Details of the investigation findings are given in Table 1. The mean CK value in 57 mothers was $270.3 \pm 417.3 \mathrm{U} / \mathrm{L}$ (52-2679) and in 20 mother the values were above the upper limit of normal (170U/L) with four individuals having more than $1000 \mathrm{U} / \mathrm{L}$. Of the 56 sisters of the probands tested for serum CK, two had values of 7420 and $23,490 \mathrm{U} / \mathrm{L}$ and in the remaining the values were normal. Intelligence Quotient (IQ) done in 81 patients showed varying degrees of mental subnormality. Of the 101 patients for whom the genetic data was available, 84 $(83.2 \%)$ patients had muscle biopsy. In $60(71.4 \%)$ of these patients immunohistochemistry was done, all of them demonstrated absence of dystrophin staining. Among the 60 dystrophin-negative cases, $44(73 \%)$ patients had deletion of at least one exon.

\section{Genetic findings}

The deletion pattern is given in Table 2. Distal hotspot Exons 45, 47, 49 and 50 were common deletions [Figure 1]. Correlation of deletions with immunohistochemistry results is depicted in Figure 2. Mild mental retardation was seen $15 \%$ of patients and all of them had at one deletion; $32.1 \%$ had borderline intelligence and $80.8 \%$ of them had at least one deletion; $27.2 \%$ had dull normal IQ and $81.8 \%$ of them had deletions; $19.8 \%$ had average

Table 2: Details of the pattern of Duchenne muscular dystrophy gene deletion

\begin{tabular}{lcc}
\hline DMD exon deletion pattern & $\mathbf{n}=\mathbf{8 3}$ & $\mathbf{\%}$ \\
\hline Single & 17 & 20.4 \\
Distal exon 45 & 30 & 36.0 \\
Distal exon 47 & 29 & 35.0 \\
Distal exon 49 & 28 & 33.7 \\
Distal exon 50 & 32 & 38.5 \\
Two or more consecutive exons & 49 & 59.0 \\
Three or more consecutive exons & 28 & 33.7 \\
Proximal hotspot & 34 & 41.0 \\
Distal hotspot & 69 & 83.0 \\
\hline
\end{tabular}

DMD: Duchenne muscular dystrophy

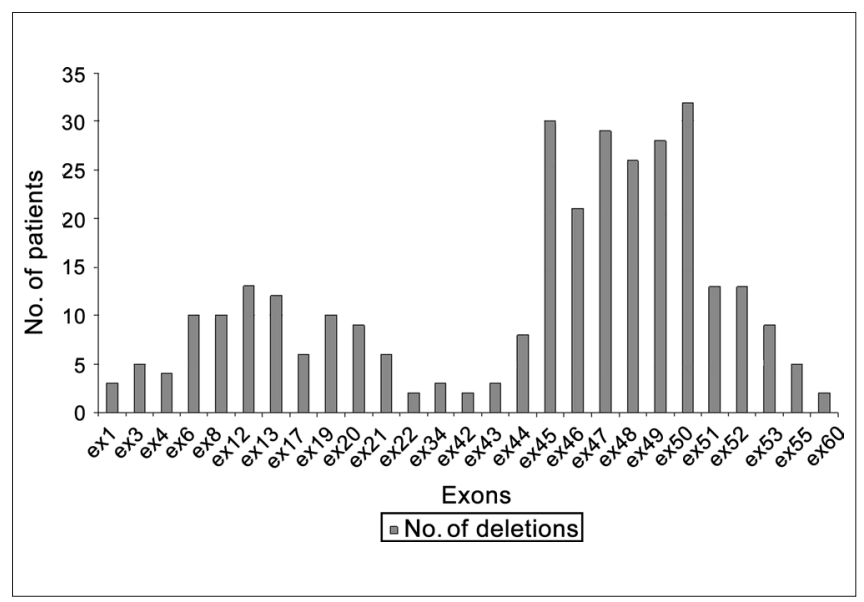

Figure 1: Graph representing exonic deletion pattern in Duchenne muscular dystrophy patients intelligence and $75 \%$ of them had deletions, $5 \%$ were with bright normal IQ and 75\% of them had deletions.

\section{Carrier testing}

Genotyping was undertaken at four short tandem repeat markers reported to have high heterozygosity viz. STR44, STR45, STR49, STR50 in the hotspot region of the dystrophin gene for 'mother and son' samples from 15 families. Six mothers were found to be carriers based on homozygosity at these marker loci. In these six families, positive family history was present in three and in the remaining three the deletions were probably new. Carrier status determination was used to study a DMD family where there was apparent paternal inheritance. ${ }^{[13]}$

\section{Discussion}

This study presents the clinical, histopathological, immunohistochemical and molecular findings in a large cohort of 101 patients with DMD from south India. Random distribution of age of onset was noted in the present study similar the earlier studies. ${ }^{[14]}$ The distribution of motor weakness was similar to that described earlier. ${ }^{[15]}$ Inter-individual variability in the clinical severity was observed among the patients and also with the families similar to the other studies. ${ }^{[16-19]}$

The reported frequency of the dystrophin gene deletions have been $22 \%$ to $86 \% \cdot{ }^{[6,20-26]}$ and dystrophin can be demonstrated by immunohistrochemistry in about $98 \%$ of DMD patients. ${ }^{[27]}$ In our cohort the diagnosis of DMD was confirmed by either the absence of dystrophin staining only (18\%) and/or exon deletions (82\%). Correlation between exonic deletion and certain clinical features like ambulation, mental retardation, and histological findings have been observed Mental retardation is seen in about one-third of DMD patients. ${ }^{[23,28]}$ In our cohort

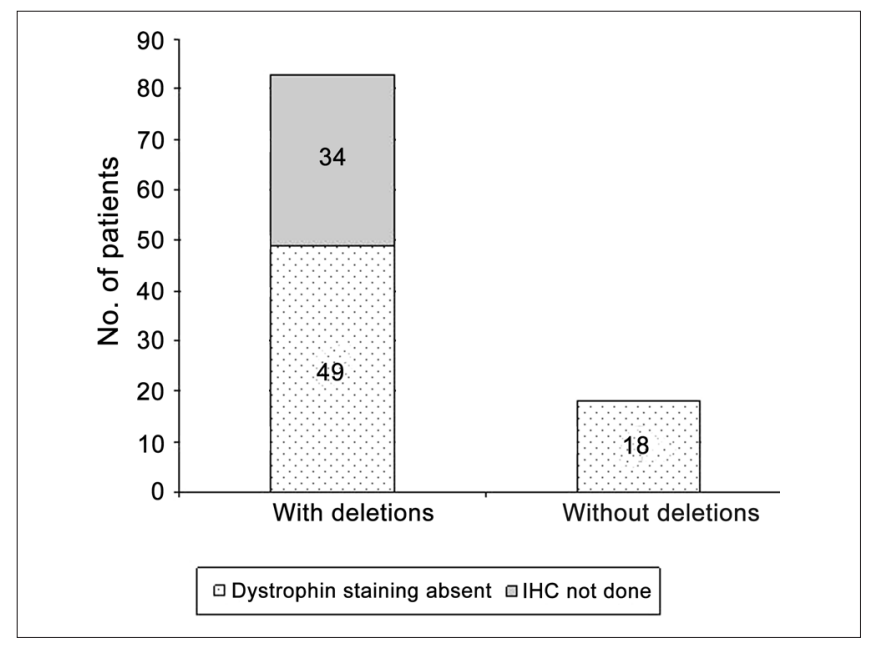

Figure 2: Graph analyzing the histopathological and deletion status among Duchenne muscular dystrophy patients 
mental retardation was seen in $48 \%$ of the patients, The lack of correlation between exonic deletions and immunohistochemical findings in $26 \%$ of the patients may be related to deletions in any of the other exons, mosaicism, or point mutation which we have not studied. Such genetic abnormalities have been documented in about $30 \%$ of cases. ${ }^{[4-7]}$

In most of the studies, $80 \%$ to $91 \%$ of deletions occurred in the distal region of the dystrophin gene ${ }^{[6,24,25]}$ and the deletion rates can be low, $42 \%$ to $52 \% .^{[6,20,22,24]}$ In the study of 160 Indian patient population from all over the country, the deletion rate was $64.4 \%$ and $69.7 \%$ of which was in the distal hotspot region. This study did not find any ethnic differences in the deletion patterns of the dystrophin gene. ${ }^{[29]}$ In the eastern Indian study the deletion rate was $63 \%$ and $79 \%$ of which was in the distal hotspot region. ${ }^{[30]}$ Singh et al., reported a deletion rate of $73 \%$ in a north Indian patient population which included both DMD and Beckers muscular dystrophy. ${ }^{[25]}$ Among a southern Indian DMD population the reported deletion rate was $62.1 \%$ and $78 \%$ of which was located in the distal hotspot region. ${ }^{[31]}$ The authors of this study concluded that the lower deletion rate in their population when compared to the north Indian population may be related to the ethnic differences in the two populations. The deletion rate reported among 25 western Indian DMD patients was $72 \%$ mostly located at the $3^{\prime}$ hotspot region. ${ }^{[32]}$ The deletion rate in our study was about $73 \%$ and was similar to the frequency reported from the other parts of India. ${ }^{[33]}$ The reported frequency of dystrophin gene deletions in other countries in Asia is quite variable: $40.7 \%$ in Pakistan, ${ }^{[34]}$ and $66.25 \%$ in China. ${ }^{[35]}$ In Egypt, an African country, it was $61.1 \% .^{[36]}$

The diagnosis of DMD is based on clinical, biochemical and histopathologic studies and further confirmed by molecular analysis. However, genetic studies should be the investigations of choice in DMD and muscle biopsy should be limited to the cases where genetic studies are not informative. Carrier state assessment and prenatal diagnosis are essential for counseling and can be offered only after the possible mutation has been identified in the proband.

\section{Acknowledgment}

The authors acknowledge the Indian Council of Medical Research (ICMR), New Delhi for financial support extended to the 'Central Molecular Genetics Laboratory for Neurology and Psychiatry'. They also thank all the members and trainees in the laboratory who helped during the course of the work, especially Ms. Sukanya, Ms. Savitha, Ms. Sumita and Ms. Tanya.

\section{References}

1. Emery AE. The Muscular Dystrophies. BMJ 1998;317:991-5.
2. Tennyson CN, Klamut HJ, Worton RG. The human dystrophin gene requires $16 \mathrm{~h}$ to be transcribed and is cotranscriptionally spliced. Nat Genet 1995;9:184-90.

3. Hoffman EP, Brown RH Jr, Kunkel LM. Dystrophin: The protein product of the Duchenne muscular dystrophy locus. Cell 1987;51:919-28.

4. Forrest SM, Cross GS, Speer A, Gardner-Medwin D, Burn J, Davies KE. Preferential deletion of exons in Duchenne and Becker muscular dystrophies. Nature 1987;329:638-40.

5. Forrest SM, Cross GS, Flint T, Speer A, Robson KJ, Davies KE. Further studies of gene deletions that cause Duchenne and Becker muscular dystrophies. Genomics 1988;2:109-14.

6. Koenig M, Hoffman EP, Bertelson CJ, Monaco AP, Feener C, Kunkel LM. Complete cloning of the Duchenne muscular dystrophy (DMD) cDNA and preliminary genomic organization of the DMD gene in normal and affected individuals. Cell 1987;50:509-17.

7. Koenig M, Beggs AH, Moyer M, Scherpf S, Heindrich K, Bettecken T, et al. The molecular basis for Duchenne versus Becker muscular dystrophy: Correlation of severity with type of deletion. Am J Hum Genet 1989;45:498-506.

8. Beggs AH, Koenig M, Boyce FM, Kunkel LM. Detection of $98 \%$ of DMD/BMD gene deletions by polymerase chain reaction. Hum Genet 1990;86:45-8.

9. Engel AG. Duchenne Dystrophy. In: Engel AG, Banker BQ, editors Myology: Basic and clinical. Vol. 2. New York: Mc Graw-Hill; 1986. p. $1185-240$.

10. Kamat VV. Measuring intelligence of Indian children. $4^{\text {th }}$ ed. Bombay: Oxford University Press; 1967.

11. Miller SD, Dykes, Polesky H. A simple salting out procedure for extracting DNA from human nucleated cells. Nucleic Acids Res 1988;16:1215.

12. Chamberlain JS, Gibbs RA, Ranier JE, Nguyen PN, Caskev CT. Deletion screening of the Duchenne muscular dystrophy locus via multiplex DNA amplification. Nucleic Acids Res 1988;9:11141-56.

13. Purushottam M, Rammurthy A, Shubha GN, Gayathri N, Nalini A. Paternal inheritance or a de novo mutation in a Duchenne Muscular Dystrophy pedigree from South India. J Neurol Sci 2008;268:179-82.

14. Dubowitz V. Muscle disorders in childhood. Major problems in clinical pediatries. London: Saunders Co. Ltd; 1978.

15. Walton J N and Gardner-Medwin D. In: Walton SJ, editor. Disorders of Voluntary Muscle. Edinburgh: Churchill Livingstone; 1981. p. 481-524.

16. Lebart. Multivariate descriptive statistical methods: Correspondence analysis and related techniques. New York: Wileey; 1984.

17. Feingold J, Feingold N, Demos J. Genes majeurs, genes modificateurs et effets du milieu dans la myopathie de duchenne de Boulogne. Ann Genet 1971;14: 207-11.

18. Brooke MH, Fenichel GM, Griggs RC, Mendell JR, Moxley R, Florence J, et al. Duchenne muscular dystrophy: Patterns of clinical progression and effects of supportive therapy. Neurology 1989;39:475-81.

19. Furukawa T, Peter JB. X-linked muscular dystrophy. Ann Neurol 1977;2:414-6.

20. Lindlöf M, Kiuru A, Kääriäinen H, Kalimo H, Lang H, Pihko H, et al. Gene deletions in X-linked muscular dystrophy. Am J Hum Genet 1989;44:496-503.

21. Hodgson SV, Abbs S, Clark S, Manzur A, Heckmatt JZ, Dubowitz V, et al. Correlation of clinical and deletion data in Duchenne and Becker muscular dystrophy, with special reference to mental ability. Neuromuscul Disord 1992;2:269-76.

22. Ballo R, Viljoen D, Beighton P. Duchenne and Becker muscular dystrophy prevalence in South Africa and molecular findings in 128 persons affected. S Afr Med J 1994;84:494-7.

23. Bresolin N, Castelli E, Comi GP, Felisari G, Bardoni A, Perani D, et al. Cognitive impairment in Duchenne muscular dystrophy. Neuromuscul Disord 1994;4:359-69.

24. Odinokova ON, Puzyrev VP, Radzhabaliev ShF, Rakhmonov RA. Deletion analysis of the dystrophin gene in patients with Duchenne's muscular dystrophy in Tajikistan. Genetika 1996;32:1392-5.

25. Singh V, Sinha S, Mishra S, Chaturvedi LS, Pradhan S, Mittal RD, et al. Proportion and pattern of dystrophin gene deletions in north Indian Duchenne and Becker muscular dystrophy patients. Hum Genet 1997;99:206-8. 
26. Haider MZ, Bastaki L, Habib Y, Moosa A. Screening 25 dystrophin gene exons for deletions in Arab children with Duchenne muscular dystrophy. Human Hered 1998;48:61-6.

27. Hoffman EP, Kunkel LM, Angelini C, Clarke A, Johnson M, Harris JB. Improved diagnosis of Becker muscular dystrophy by dystrophin testing. Neurology 1989;39:1011-7.

28. Dubowitz V. Muscle disorders in Childhood. London: Saunders; 1995.

29. Banerjee M, Verma IC. Are there ethnic differences in the dystrophin gene? Am J Med Genet 1997;68:152-7.

30. Basak J, Dasgupta UB, Banarjee TK, Senapati AK, Das SK, Mukherjee SC. Analysis of dystrophin gene deletions by multiplex PCR in eastern India. Neurology India 2006;54:310-1.

31. Mallikarjuna Rao GN, Hussain T, Geetha-Devi N, Jain S, Chandak GR, Ananda Raj MP. Dystrophin gene deletions in South Indian Duchenne muscular dystrophy patients. Indian J Med Sci 2003;57:1-6.

32. Khalap NV, Joshi VP, Ladiwalla U, Khadilkar SV, Mahajan SK. A report on higher frequency of DMD gene deletion in the Indian subcontinent. Indian J Hum Genet 1997;3:117-20.
33. Nadkarni JJ, Dastur RS, Viswanathan V, Gaitonde PS, Khadilkar SV. Duchenne and Becker muscular dystrophies: An Indian update on genetics and rehabilitation. Neurol India 2008;56:248-53.

34. Hassan MJ, Mahmood S, Ali G, Bibi N, Waheed I, Rafiq MA, et al. Intragenic deletions in the dystrophin gene in 211 Pakistani Duchenne muscular dystrophy patients. Pediatr Int 2008;50:162-6.

35. Wang X, Wang Z, Yan M, Huang S, Chen T.J, Zhong N. Similarity of DMD gene deletion and duplication in the Chinese patients compared to global populations. Behav Brain Funct 2008;29:4:20.

36. El Sherif RM, Fahmy NA, Nonaka I, Etribi MA. Patterns of dystrophin gene deletion in Egyptian Duchenne/Becker muscular dystrophy patients. Acta Myol 2007;26:145-50.

Accepted on 25-04-2009

Source of Support: The Indian Council of Medical Research (ICMR),

New Delhi for financial support extended to the 'Central Molecular

Genetics Laboratory for Neurology and Psychiatry'. Conflict of

Interest: None declared. 